\title{
Scaling up community-based cervical cancer screening in Cameroon employing a single visit approach
}

\author{
Damien Grohar, Geneva, Switzerland; Pierre Vassilakos, Geneva, Switzerland; Khadidja Benkortbi, Geneva, \\ Switzerland; Evelyn Tincho, Dschang, Cameroon; Bruno Kenfack, Dschang, Cameroon and Patrick Petignat, Geneva, \\ Switzerland
}

Cervical cancer caused by persistent human papillomavirus (HPV) infection is still a major public health concern in subSaharan Africa. In Cameroon it represents the second most common cancer in women and the leading cause of cancer-related deaths. As in many other parts of subSaharan Africa, facilities for the prevention and treatment of this cancer are still very limited in this country.

Launched in September 2018 in partnership with the Cameroon Ministry of Public Health, the Dschang District Hospital and University Hospitals of Geneva, we designed a 5-year community-based cervical cancer screening program in West Cameroon ${ }^{1}$ (Figure 1). Historically, since 1980, a partnership has existed between the University of Geneva and the Cameroonian Ministry of Health with the aim of developing knowledge and promoting its exchange. In the domain of cervical cancer prevention, the partnership was established in 1999 and has led to the development of a highly productive research platform for medical students and young doctors. ${ }^{2-5}$

Our screening program, based on the WHO recommendation, entitled the '3T-Approach' (Test, Triage and Treat), is done in a single visit (Figure 2). Briefly, after counselling, a point-of-care rapid HPV self-test is performed followed by visual triage for

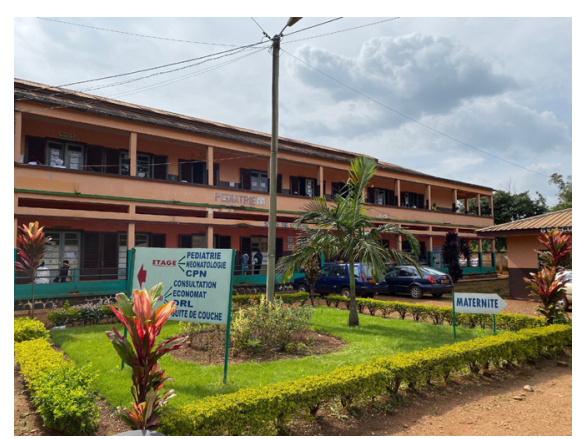

Figure 1 District Hospital of Dschang, Cameroon.

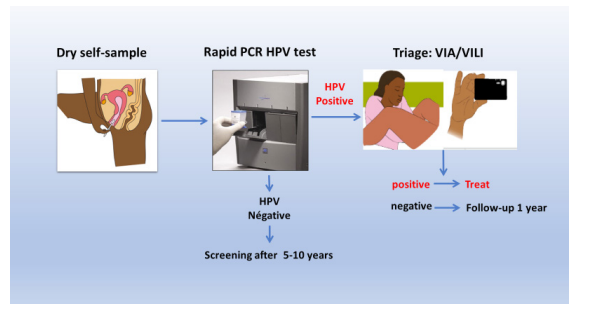

Figure 2 '3T-Approach' strategy procedure - 1 day visit. Self-sampling with a dry swab is followed by rapid human papillomavirus (HPV) testing (Xpert ${ }^{\mathrm{TM}}$ HPV). HPV-negative women are reassured and advised to do the next screening 5 years later. HPVpositive women will undergo visual inspection with acetic acid and visual inspection with iodine (VIA/VILI) and treatment (if indicated) or follow-up. Smartphone digital photographs (cervicograms) are obtained for quality control. Source: Vassilakos et al, Rev Med Suisse (March 2019).

HPV-positive women and treatment with thermal ablation if needed Figure 3. Smartphone digital photographs after visual inspection with acetic acid (VIA) and visual inspection with Lugol's iodine (VILI) (D-VIA VILI) are also obtained for quality control as well as cytology, biopsies, and endocervical brushing for program evaluation (Figure 4). We decided to organize and sustain our

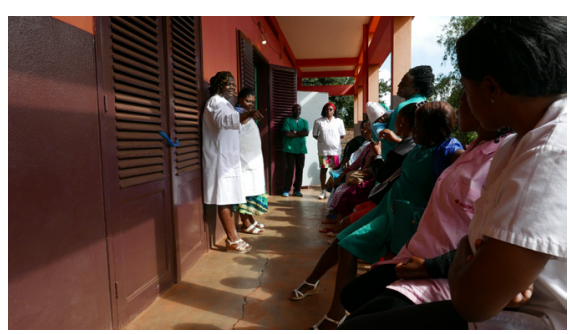

Figure 3 District Hospital of Dschang: women receive counselling service (communityeducation, counselling on sexual health and cervical cancer screening) before testing.

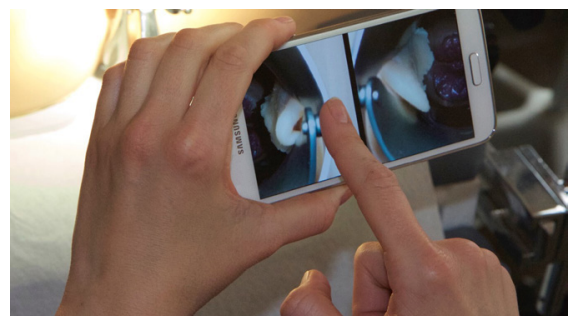

Figure 4 Smartphone digital images acquisition after VIA (D-VIA) and VILI (D-VILI) procedures. This allow to slide between pictures on the Smartphone for diagnosis. It is a simple and reproducible procedure that facilitates the identification of lesion.

program in a well-defined geographical area of West Cameroon (Dschang Health District) before expanding to cover the region. In this brief contribution we report our 18-month experiences and achievements in an ongoing community-based cervical cancer screening program.

\section{CERVICAL CANCER SCREENING PROGRAM (3T-APPROACH) \\ Setting}

The program started in the city of Dschang and surrounding villages in September 2018. We estimated that about 10000 women in this zone aged $30-49$ years were eligible for a cervical cancer screening test. Screening coverage is regularly monitored for communication and intervention planning with community health workers in order to enhance participation of women in the program (Figure 5). Social educators trained to provide information about cervical cancer and its screening play a major role. They provide information in villages, churches, markets, and women's associations and encourage women to participate. They educate people on positive health-seeking behaviors, about the importance of HPV infection and timely screening 


\section{Corners of the world}

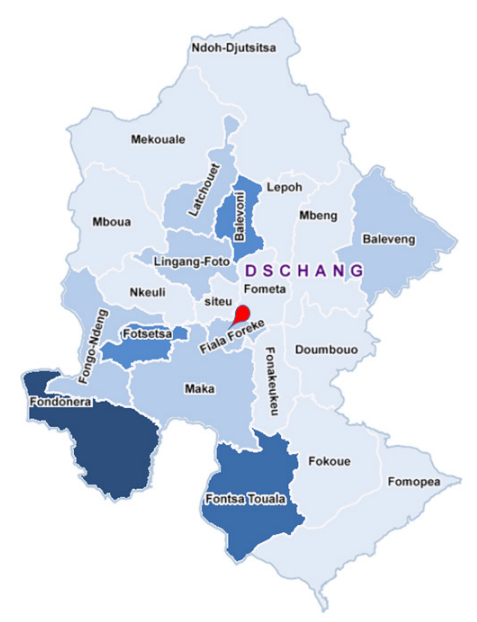

Figure 5 District of Dschang, West Cameroon. A detailed map allows monitoring and evaluation of screening coverage rates (women 30-49 years). This is an example of a map showing rates of coverage during the second half of 2019.

and treatment of pre-cancerous lesions. A free consultation is emphasized.

\section{Training of staff}

Local staff were trained through an e-learning process (www.gfmer.ch) and with on-site training conducted by physicians from the University of Dschang and Geneva University Hospitals. One week of a theoretical course followed by 1 week of practical training on VIA, VILI, Smartphone images acquisition and thermal ablation using anatomical models was given to healthcare providers performing the screening (Figure 6). After 2 weeks of training, a review of photographs of normal and abnormal cervix as well as clinical sessions to observe and practice the techniques were organized. At the end of the training, a theoretical and practical examination was performed to ensure that all the necessary skills were acquired. Healthcare providers received certification after an examination from the University of Dschang and Geneva.

\section{Program monitoring and evaluation}

A set of benchmark indicators was developed to quantitatively evaluate how the screening and treatment program is progressing towards expected results. This permits early detection of potential problems. Results-at-a-Glance posters are given periodically to the staff in order to assess the screening performance. Based on our previous studies, we defined nine

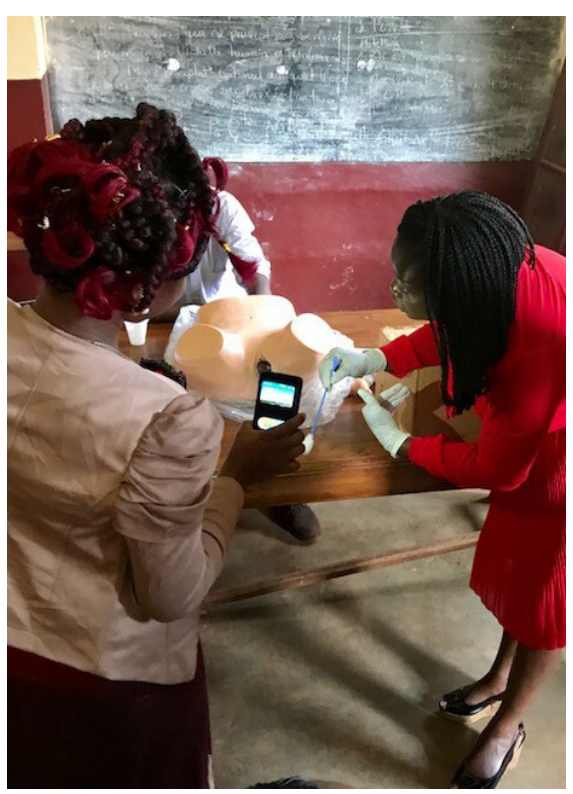

Figure 6 Smartphone training of health care providers for VIA and VILI digital image acquisition (D-VIA/D-VILI). and referral decisions. Digital images of the cervix are also used for education (photos for review meetings and case studies).

\section{Performance of the visual triage (VIA/ VILI)}

We use 'relaxed WHO criteria', meaning that any aceto-white lesion with faint whitening in the transformation zone is considered as VIA-positive. A VILI-positive test is defined as an iodo-negative area that takes a mustard or saffron yellow color. To examine the performance characteristics of VIA/ VILI among HPV-positive women, standard test metrics (sensitivity, specificity, positive predictive value, and negative predictive value) are calculated. Results from histopathological examinations of cervical tissue obtained from biopsies and endocervical brushing are used as the gold standard to evaluate accuracy. Guided biopsies are performed on all visible lesions. If no lesion

Table 1 Performance monitoring indicators and targets for the screening program

\begin{tabular}{ll}
\hline Indicator & Target \\
\hline $\begin{array}{l}\text { Screening rate: target population Dschang } \\
\text { 10 } 000 \text { women, 30-49 years }\end{array}$ & 2000 per year \\
$\begin{array}{l}\text { Percentage of women having completed } \\
\text { the single-visit 3T-approach }\end{array}$ & $\geq 90 \%$ \\
$\begin{array}{l}\text { Percentage of HPV-positive women } \\
\text { Percentage of HPV-positive women who }\end{array}$ & $>95 \%$ \\
received VIAVILI & \\
Percentage of VIAVILI-positive cases & $40-55 \%$ \\
$\begin{array}{l}\text { Percentage of VIAVILI-positive cases who } \\
\text { received treatment }\end{array}$ & $\geq 90 \%$ \\
$\begin{array}{l}\text { Follow-up rate after treatment: } 1 \text { month, } 6 \\
\text { months, } 12 \text { months }\end{array}$ & $\geq 80 \%, \geq 70 \%$, \\
$\begin{array}{l}\text { Major incident rate during or after } \\
\text { thermoablation or LEEP }\end{array}$ & $<1 \%$ \\
$\begin{array}{l}\text { Percentage of HPV-positive women VIA/ } \\
\text { VILI-negative returned for a control }\end{array}$ & $\geq 70 \%$ \\
\hline HPV, human papillomavirus; LEEP, loop electrosurgical excision \\
procedure; VIAVILI, visual inspection with acetic acid/visual \\
inspection with Lugol's iodine.
\end{tabular}

indicators including corresponding targets against which performance is assessed (Table 1).

\section{Ongoing training of providers}

In order to enhance program performance, all providers met weekly with a supervising consultant gynecologist to review and discuss the digital images (D-VIA/VILI) of HPV-positive women and discuss treatment is seen, a random biopsy from 6 o'clock within the transformation zone and near the squamo-columnar junction are obtained accompanied by an endocervical brushing.

\section{Cure rate and evaluation of overtreatment at 12 months}

Cure rate was defined as the percentage of women with no evidence of disease at 
12 months after a baseline diagnosis of cervical intra-epithelial neoplasia (CIN) 2 or CIN 3. Overtreatment was defined as treatment of women who either had no lesion or had CIN 1 lesions on baseline cervical biopsies and endocervical curettage and cytology was negative for a high grade squamous intra-epithelial lesion.

\section{Cost analysis of the program}

Cost analysis of the 5-year program will include staff time and salaries, clinical and laboratory supplies, laboratory and treatment equipment, start-up costs, training, and community mobilization costs. This also includes the cost for treatment of patients with invasive cancer diagnosed after screening. Additionally, we will analyze costs per woman and per pre-cancer and cancer diagnosed through a 5-year period modeling.

\section{CONCLUSION}

Considering the local specificities and available resources, we believe after 18 months of implementation and experience in Dschang that the program can be expanded to the region at large. Key pillars for the success of the program include providing adequate training and educational tools as well as developing a culture of quality among the healthcare workers. Future reports on clinical outcomes and cost analysis will contribute to optimizing a strategic plan for cervical cancer prevention in lowand middle-income countries.

Correspondence to Professor Patrick Petignat, Department of Gynaecology and Obstetrics, University Hospitals of Geneva, 1205 Genève, Switzerland; patrick.petignat@hcuge.ch

Acknowledgements The authors would like to thank Chloé Frund, Jessica Sormani, Jovanny Fougue, Alexia Chatillon, Christine Balli, Hélène Gaitsch, Karolin Tatrai, Rosa Catarino, Fritz Baumann, Beat Stoll, Atem Bethel Ajong.

Contributors All the authors made contributions to the design and participated in drafting and revising the manuscript. All authors gave final approval of the submitted version.

Funding This research is supported by the University Hospitals of Geneva (Commission des Affaires Humanitaires (CAH)), Solidarité Internationale Genève, ESTHER Switzerland Partnership Project Grant (17G1), District Hospital of Dschang. The authors have not declared a specific grant for this research from commercial sectors.

Competing interests None declared.

Patient consent for publication Not required.

Provenance and peer review Commissioned; internally peer reviewed.

(c) IGCS and ESGO 2020. No commercial re-use. See rights and permissions. Published by BMJ.

Check for updates
To cite Grohar D, Vassilakos P, Benkortbi K, et al. Int J Gynecol Cancer 2020;30:1455-1457.

Accepted 27 March 2020

Published Online First 4 May 2020

Int J Gynecol Cancer 2020;30:1455-1457.

doi:10.1136/ijgc-2020-001422

\section{REFERENCES}

1 Vassilakos P, Tebeu P-M, Halle-Ekane GE, et al. Fritz Baumann et Patrick Petignat. Vingt années de lutte contre le cancer du col utérin en Afrique subsaharienne - collaboration médicale entre Genève et Yaoundé. Revue Médicale Suisse 2019;15:601-5.

2 Untiet S, Vassilakos P, McCarey C, et al. HPV self-sampling as primary screening test in sub-Saharan Africa: implication for a triaging strategy. Int $J$ Cancer 2014;135:1911-7.

3 Fokom-Domgue J, Combescure C, Fokom-Defo V, et al. Performance of alternative strategies for primary cervical cancer screening in sub-Saharan Africa: systematic review and meta-analysis of diagnostic test accuracy studies. BMJ 2015;351.

4 Catarino R, Petignat P, Dongui G, et al. Cervical cancer screening in developing countries at a crossroad: emerging technologies and policy choices. World $\mathrm{J}$ Clin Oncol 2015;6:281-90.

5 Tebeu P-M, Fokom-Domgue J, Crofts V, et al. Effectiveness of a two-stage strategy with HPV testing followed by visual inspection with acetic acid for cervical cancer screening in a low-income setting. Int J Cancer 2015;136:E743-50. 